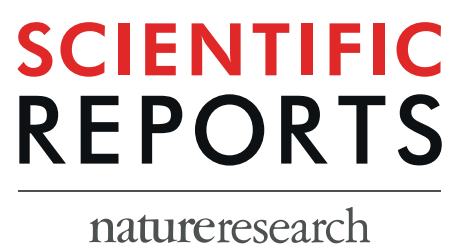

\title{
Genetic and epigenetic alterations induced by bisphenol A exposure during different periods of spermatogenesis: from spermatozoa to the progeny
}

Marta Lombó ${ }^{1}$, Cristina Fernández-Díez ${ }^{2}$, Silvia González-Rojo ${ }^{1}$ \& María Paz Herráez ${ }^{1 *}$

Exposure to bisphenol A (BPA) has been related to male reproductive disorders. Since this endocrine disruptor also displays genotoxic and epigenotoxic effects, it likely alters the spermatogenesis, a process in which both hormones and chromatin remodeling play crucial roles. The hypothesis of this work is that BPA impairs early embryo development by modifying the spermatic genetic and epigenetic information. Zebrafish males were exposed to 100 and $2000 \mu \mathrm{g} / \mathrm{L}$ BPA during early spermatogenesis and during the whole process. Genotoxic and epigenotoxic effects on spermatozoa (comet assay and immunocytochemistry) as well as progeny development (mortality, DNA repairing activity, apoptosis and epigenetic profile) were evaluated. Exposure to $100 \mu \mathrm{g} / \mathrm{L} \mathrm{BPA}$ during mitosis slightly increased sperm chromatin fragmentation, enhancing DNA repairing activity in embryos. The rest of treatments promoted high levels of sperm DNA damage, triggering apoptosis in early embryo and severely impairing survival. Regarding epigenetics, histone acetylation (H3K9AC and H3K27Ac) was similarly enhanced in spermatozoa and embryos from males exposed to all the treatments. Therefore, BPA male exposure jeopardizes embryonic survival and development due to the transmission of a paternal damaged genome and of a hyper-acetylated histone profile, both alterations depending on the dose of the toxicant and the temporal window of exposure.

Bisphenol A (BPA; 2,2-bis(4-hydroxyphenyl)propane] was firstly used to enhance the growth of cattle and poultry due to its estrogenic activity, but its actual future would be in epoxy resins and plastic industry ${ }^{1}$. Since 1957, when chemists at Bayer and General Electric discovered that once this compound polymerizes it produces a hard plastic (known as polycarbonate), it has become an essential component for the manufacturing of beverage and feeding bottles, electronic devices, thermal paper, medical instruments, dental materials, and so on ${ }^{2,3}$. Owing to its widespread use in domestic and industrial products, the presence of BPA is ubiquitous: it has been detected in air, soil, water and food, from where it is able to migrate to urine, saliva, skin, blood, breast milk and even, amniotic fluid ${ }^{4,5}$. Despite the high variation of BPA concentrations in the environment, sewage effluents and landfill leachates have turned aquatic systems into the most common source of contamination, BPA concentrations rating from $\mathrm{nM}$ concentrations in river water samples to $\mathrm{mM}$ concentrations in landfill leachates as reviewed by Crain and colleagues ${ }^{6}$. The continuous exposure to this toxicant has been related to health problems in animal models, wildlife and humans ${ }^{7}$.

As summarized by Almeida and colleagues ${ }^{8}$, BPA displays a wide range of effects including diabetes, cardiovascular diseases, abnormalities in behavior and immune function, breast cancer and infertility. The deleterious effect of BPA on male reproductive function may happen during embryonic, pubertal and/or adult life ${ }^{9}$. During these last two periods of life, spermatogonial stem cells multiply and differentiate into mature spermatozoa, process known as spermatogenesis, which takes place in the extremely regulated microenvironment of the testis ${ }^{4}$. Although the gonadotropins LH (luteinizing hormone) and FSH (follicle stimulating hormone) are the most

${ }^{1}$ Department of Molecular Biology, Faculty of Biology and Environmental Sciences, Universidad de León, Campus de Vegazana, León, 24071, Spain. ${ }^{2}$ Instituto Ganadero de Motaña (IGM), Finca Marzanas-Grulleros Vega de Infanzones, León, 24346, Spain. *email: paz.herraez@unileon.es 
important hormones in charge of the regulation of testicular physiology, both thyroid and steroid hormones (estrogens and androgens) also play a crucial role on fish spermatogenesis ${ }^{10,11}$. Mackay and colleagues ${ }^{7}$ reviewed that BPA is an endocrine disruptor able to bind not only to estrogen receptors but also to androgen, thyroid hormone and estrogen-related receptors, so it likely interferes in any step of sperm cell formation ${ }^{3}$. In fact, BPA has been reported to induce restructuring of rat blood-testis barrier ${ }^{12}$ and to reduce sperm count and quality in many different species ${ }^{13}$.

Although it is widely known that BPA affects male reproduction owing to its endocrine disruptive capacity $^{13-15}$, little is known about the mechanisms of inheritance to subsequent generations non-exposed to the toxicants. In that regard, both genotoxic and epigenotoxic effects on the germline cells might well lie behind the paternal transmission of the toxic effects to the progeny that have been previously reported ${ }^{16}$.

As far as the genotoxic effects are concerned, exposure to BPA has been described to cause meiotic arrest, to induce meiotic aneuploidy and chromosome aberrations, and to inhibit meiotic double strand breaks (DSBs) repair $^{17-19}$. Moreover, adult male exposure to BPA has been reported to induce persistent DSBs in pachytene spermatocytes and to disrupt meiotic progression in rat and in zebrafish ${ }^{20,21}$. Despite the alterations occurred in the male germline, zygote still has the chance to manage this information and to mend some errors which are presumably inconsistent with proper embryo development. Even though maternal repairing machinery is essential to fix sperm DNA damage ${ }^{22}$, embryos also develop strategies to face unrepaired damage: they activate different pathways for detecting damaged $\mathrm{DNA}^{23,24}$ and, eventually, they decide whether fixing or tolerating the harm to keep on developing (if the damage is moderate) ${ }^{25}$ or inducing apoptotic activity and senescence (when DNA is harshly damaged) ${ }^{23,26,27}$.

Historically, spermatozoa have been considered as mere vectors, whose function was limited to deliver the haploid paternal genome to an oocyte during fertilization. Nowadays, much more attention has been paid to the role of paternal contribution on embryo development ${ }^{28-30}$. Albeit very specialized, sperm cells still handle much information that goes beyond nuclear DNA transmitted to the oocyte. The epigenetic landscape of spermatozoa is also transmitted and, therefore, it may have an impact on offspring health ${ }^{28,31,32}$. Throughout the spermatogenesis, the different cell populations suffer an intense remodelling of the epigenetic information, which involves inheritable modifications altering gene expression that do not change primary DNA sequence, such as DNA methylation, post-translational histone modifications as well as coding and non-coding RNAs ${ }^{28,33}$. Therein lies another important target of BPA, whose epigenetic toxicity has already been associated with reproductive disorders $^{34}$. Concerning DNA methylation, BPA has been reported to cause both global hypomethylation in human spermatozoa ${ }^{35}$ and zebrafish testis ${ }^{36}$ and hypermethylation in mouse spermatocytes ${ }^{37}$ Changes in histone acetylation triggered by BPA are also dependent of doses and species: long-term exposure to a low dose of BPA led to a decrease in histone acetylation in rat testes ${ }^{38}$, whereas exposure to high doses of BPA induced an increase in histone acetylation in zebrafish testes ${ }^{21}$. Regarding epigenetic aberrations, embryos at early stages of development undergo a reprogramming of epigenetic marks, so they have the potential to erase and correct most epimutations carried by the spermatozoa ${ }^{9,16}$. Nevertheless, some environmentally-induced epigenetic defects can be inherited through paternal via by subsequent generations when these changes occur in elements escaping from remodelling, such as imprinted genes, or when the enzymes in charge of the epigenetic reprogramming are affected ${ }^{39-41}$.

Taking all these data into account, the aim of this work is to determine whether paternal BPA exposure during different periods of the spermatogenesis- when unique molecular modifications are being established-is able to alter the information contained in the spermatozoa, thus jeopardizing embryo development. For this purpose, we have used zebrafish (Danio rerio) as model species since its spermatogenesis has been deeply described ${ }^{42}$ and its early development is easy to monitor due to its external fertilization and the transparency of embryos ${ }^{43}$.

\section{Results}

Spermatozoa DNA fragmentation. The evaluation of DNA integrity in sperm cells revealed an increase in the number of cells with fragmented DNA displaying a different pattern of distribution among treatments, which depends not only on the BPA dose but also on the time of exposure (Fig. 1A,B). Regarding short exposure, around $46 \%$ of sperm cells from males treated with $100 \mu \mathrm{g} / \mathrm{L}$ BPA showed less than $10 \%$ of DNA fragmentation, whereas $27 \%$ of cells from males exposed to $2000 \mu \mathrm{g} / \mathrm{L}$ BPA had between 40 and $50 \%$ of their DNA fragmented (Fig. 1A). As for long exposure to $100 \mu \mathrm{g} / \mathrm{L} \mathrm{BPA}$, there was a decrease in the percentage of low-damaged sperm cells: $30 \%$ had less than $10 \%$ of fragmented DNA, whereas all the spermatozoa from males exposed to $2000 \mu \mathrm{g} / \mathrm{L}$ BPA exhibited DNA fragmentation higher than $40 \%$; in fact, $29 \%$ of these cells had between 70 and $80 \%$ of fragmented DNA (Fig. 1B).

Sperm epigenetics. The assessment of epigenetic landscape of spermatozoa revealed that methylation of spermatozoa was not modified after exposing males to BPA (Supplemental Material, Fig. S2A, B) but two different acetylation marks did change after BPA exposure. Short exposure to both doses of BPA caused an increase in H3K27Ac and long exposure to the highest dose of BPA remarkably increased the acetylation of H3K9Ac (Fig. 2).

Embryo mortality. The mortality of embryos from control and males exposed to BPA during 2 and 3 weeks was evaluated from the first $24 \mathrm{hpf}$ to $120 \mathrm{hpf}$. The results, indicated as percentage of cumulative mortality, showed a high increase in batches obtained from BPA-exposed males. Particularly, short exposure to $2000 \mu \mathrm{g} / \mathrm{L}$ BPA greatly increased F1 mortality but it never exceeded 94\% (Fig. 3A). However, long exposure to the highest dose of BPA, led to $100 \%$ of embryonic mortality already at 48 hpf (Fig. 3B).

Embryonic DNA repairing activity. The activation of DNA damage signalling in the embryos was assessed at $3.3 \mathrm{hpf}$ via two markers: $\gamma \mathrm{H} 2 \mathrm{AX}$ and 53BP1, whose combination in the nuclei gives rise to the repairing foci. The progeny from males exposed to $100 \mu \mathrm{g} / \mathrm{L}$ BPA during mitotic phase displayed an increase in these two proteins (Fig. 4A,B) and a high level of their co-localization (Fig. 4C). None of these results were reproduced by the 
A

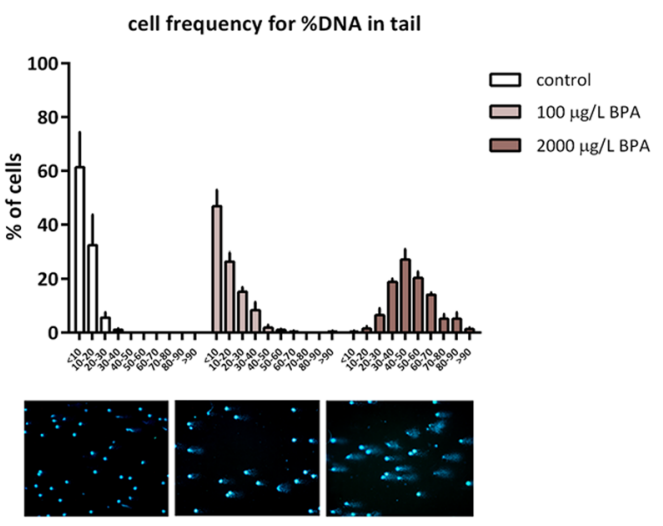

B

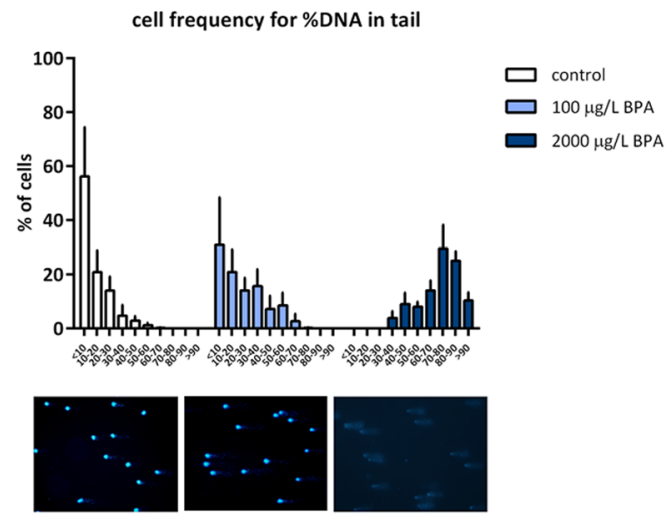

Figure 1. Percentage of spermatozoa in each rate of tail DNA in: (A) males exposed to BPA during mitotic phases and (B) during the whole spermatogenesis. Bars represent percentage of 4 pools of sperm cells from 4 males per treatment $(\mathrm{n}=4)$.

offspring of males treated with $2000 \mu \mathrm{g} / \mathrm{L}$ BPA. Concerning the progeny from males exposed during the whole spermatogenesis, there was a decrease in $\gamma \mathrm{H} 2 \mathrm{AX}$ in embryos from males treated with the two doses of BPA (Fig. 5A) and a reduction in 53BP1 of embryos from males exposed to $2000 \mu \mathrm{g} / \mathrm{L} \mathrm{BPA}$ (Fig. 5B). The study of co-localization did not indicate any formation of repairing foci (Fig. 5C).

Apoptotic activity. The results revealed that the apoptotic activity of F1 embryos obtained from males treated with $2000 \mu \mathrm{g} / \mathrm{L}$ BPA during early spermatogenesis reached $49.6 \%$, being significantly higher than in control batches (Fig. 6A) and it also increased in F1 embryos up to $68.2 \%$ and $51.9 \%$ when males were exposed to $100 \mu \mathrm{g} / \mathrm{L}$ and $2000 \mu \mathrm{g} / \mathrm{L} \mathrm{BPA}$, respectively, during the whole spermatogenesis (Fig. 6B).

Yolk syncytial layer formation. Immunostaining with phalloidin, which clearly showed the cell cortex in the blastomeres, showed that embryos from treatments without the ability to form repairing foci in which the apoptosis was enhanced, displayed an abnormal development of yolk syncytial layers (YSL), which resulted hypertrophied (Fig. 6C,D). This syncytium consists of an extra-embryonic tissue formed by the tenth cell division (during the blastula stage) in all teleost fishes.

Embryonic epigenetics. Methylation. The analysis of global DNA methylation $(5 \mathrm{mC})$ at $3.3 \mathrm{hpf}$ did not reveal any difference among embryos from control and males exposed to BPA during any period of spermatogenesis. The expression analysis of several DNA-methyltransferases (dnmts) at this stage of development did not show any alterations either (Supplemental Material, Fig. S2).

Acetylation. The evaluation of histone acetylation in embryos at $3.3 \mathrm{hpf}$ showed modifications in several marks. There was an increase in acetylation of lysine 9 in histone 3 (H3K9Ac) of embryos from males exposed to 2000 $\mu \mathrm{g} / \mathrm{L}$ BPA during both periods of spermatogenesis (Fig. 7A,B). Furthermore, acetylation of lysine 27 in histone 3 (H3K27 Ac) was also increased in the offspring from males exposed to BPA during mitotic phase (Fig. 7E) and the rise in acetylation of lysine 12 in histone $4(\mathrm{H} 4 \mathrm{~K} 12 \mathrm{Ac})$ was observed in embryos from males exposed to $100 \mu \mathrm{g} / \mathrm{L}$ BPA during the whole spermatogenesis (Fig. $7 \mathrm{H}$ ).

Additionally, expression of three enzymes involved in histone acetylation was evaluated at $24 \mathrm{hpf}$ : kat $6 a$ (histone acetyltransferase), hdac4 and hdac6 (histone deacetylases). Results revealed an overexpression of kat6a in embryos from males treated 2 weeks with $2000 \mu \mathrm{g} / \mathrm{L} \mathrm{BPA} \mathrm{(Fig.} \mathrm{8A).} \mathrm{In} \mathrm{contrast,} \mathrm{exposure} \mathrm{to} 100 \mu \mathrm{g} / \mathrm{L}$ BPA during 3 weeks led to an upregulation of $h d a c 4$ (Fig. 8B).

\section{Discussion}

Several studies have reported that exposure to environmental pollutants may lead to alterations of the information contained in the spermatozoa, thus endangering the health of subsequent generations ${ }^{44,45}$. It is also known that the risk of disease as well as its transmission depends on the susceptibility window during which the exposure to the toxicant takes place ${ }^{9}$. Spermatozoa are exceptionally specialized cells formed through a differentiation process which involves mitotic expansion of spermatogonia, meiotic phase when primary and secondary spermatocytes are generated and, eventually, the spermiogenesis, a process in which haploid spermatids turn into motile and flagellated spermatozoa ${ }^{10}$. Understandably, different molecular mechanisms lie behind each of these mentioned steps including among others chromatin compaction, which implies transient DNA strand breaks ${ }^{46}$ and epigenetic events in DNA and its associated histones ${ }^{47}$. Our findings clearly demonstrate that both genetic and epigenetic information of sperm cells, as well as F1 early embryo, are decidedly altered after paternal exposure to BPA during two different periods of spermatogenesis: one involving only mitotic phase and another one affecting the whole process of spermatogenesis. And, what is more, most of these effects vary in a time-dependent manner. 
A

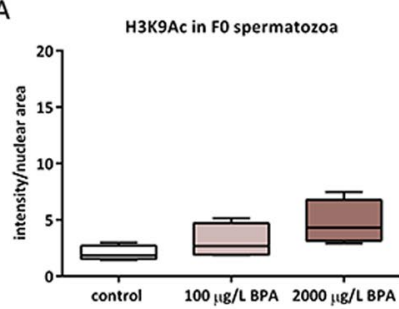

C

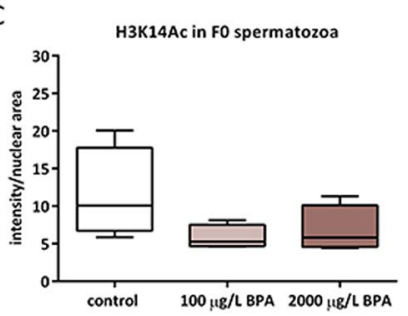

$\mathrm{E}$

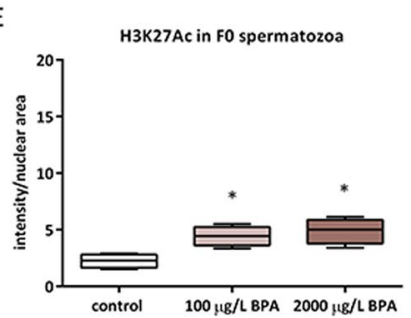

G

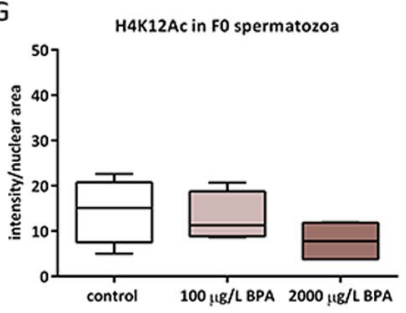

B

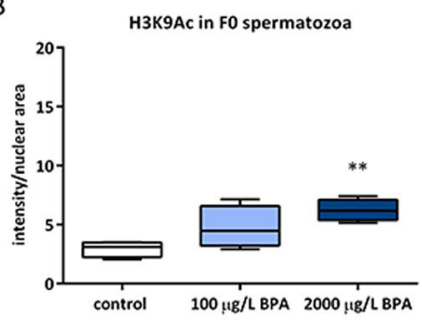

D

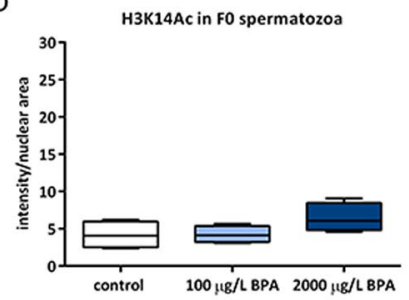

$\mathrm{F}$

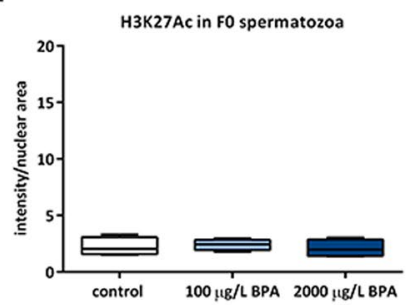

$\mathrm{H}$

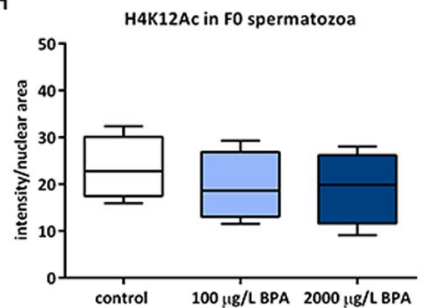

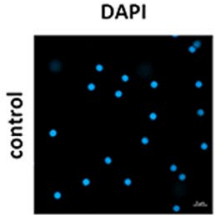
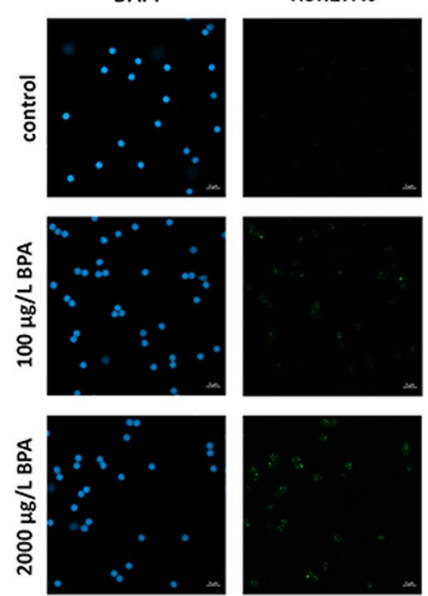

DAPI
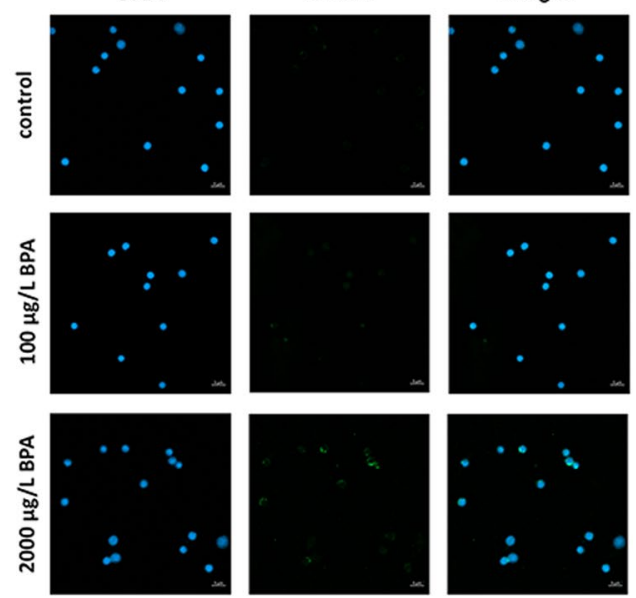

Figure 2. Quantification of histone acetylation marks: H3K9 (A,B), H3K14 (C and D), H3K27 (E,F) and $\mathrm{H} 4 \mathrm{~K} 12(\mathbf{G}, \mathbf{H})$ in spermatozoa from males exposed to BPA during mitotic phase as well as the whole spermatogenesis, respectively. Boxes represent nuclear intensity of Alexa Fluor 488 in spermatozoa from 4 males per treatment $(\mathrm{n}=4)$. Asterisks indicate significant differences $(* \mathrm{p}<0.05 ; * * \mathrm{p}<0.01)$ when comparing to control group. Representative images of histone acetylation at $100 \mathrm{X}$ (scale bar $=5 \mu \mathrm{m}$ ) appeared in: (I) H3K27Ac in spermatozoa from males exposed to BPA during mitotic phase and (J) H3K9Ac in spermatozoa from males exposed to BPA during all the spermatogenesis.

A

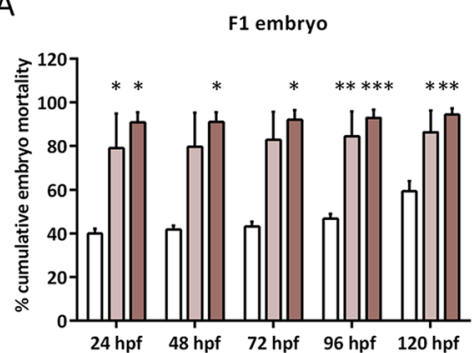

B

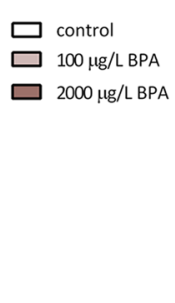

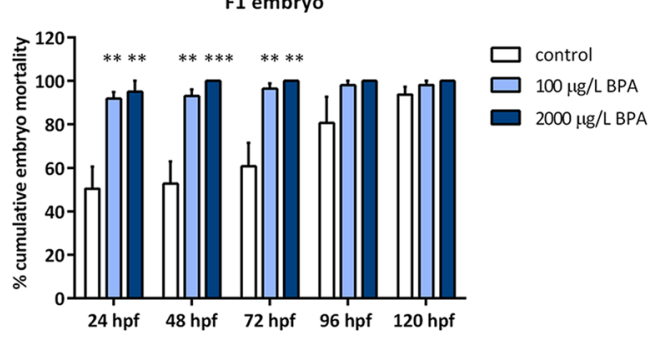

Figure 3. Percentage of embryo mortality throughout 120 hours of embryo development in: embryo obtained from males exposed to ethanol and BPA during mitotic phase of spermatogenesis (A) and males exposed during the whole spermatogenesis $(B)$. Bars represent 4 batches of control and treated embryos $(n=4)$. Asterisks indicate significant differences $(* * \mathrm{p}<0.01 ; * * * \mathrm{p}<0.001)$ when comparing to control group.

BPA exposure during mitotic phase triggered an increase in the percentage of embryo mortality, reaching $94 \%$ in the progeny from males exposed to the highest dose. After this period of exposure, half of the spermatozoa from males treated with $100 \mu \mathrm{g} / \mathrm{L}$ BPA showed a slight decrease in DNA integrity (around $46 \%$ of sperm cells from 
A $\gamma \mathrm{H} 2 \mathrm{AX}$ in $3.3 \mathrm{hpf} \mathbf{F} 1$ embryo

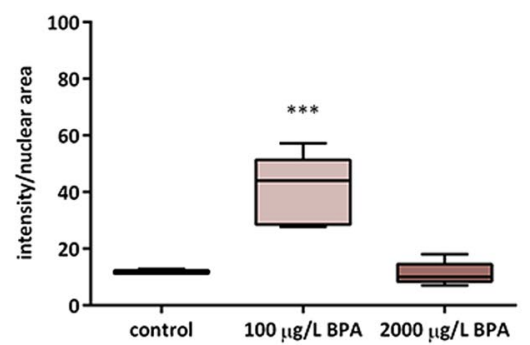

C

DAPI
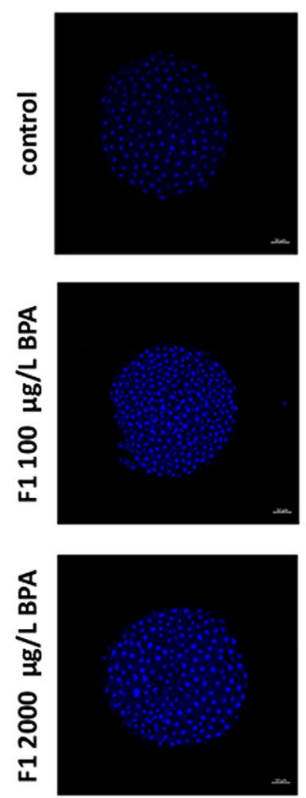

YH2AX
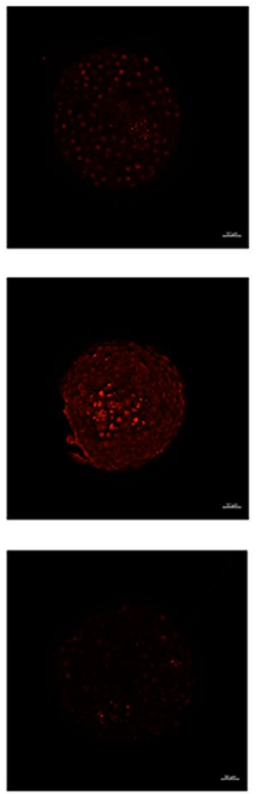

B

53BP1 in 3.3hpf F1 embryo

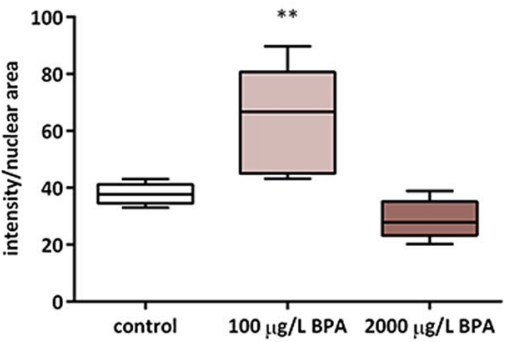

53BP1
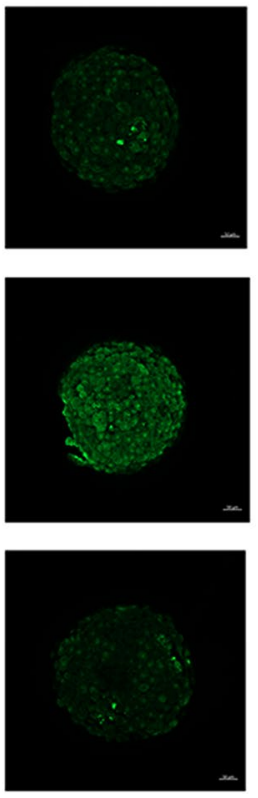

merged
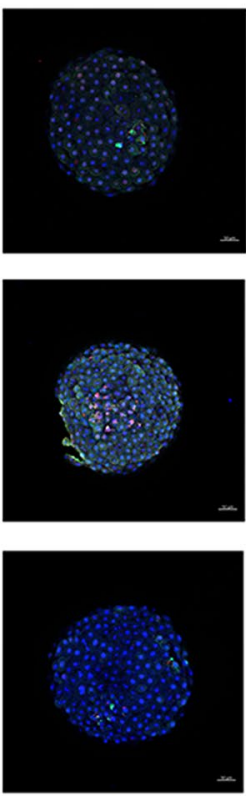

repairing foci
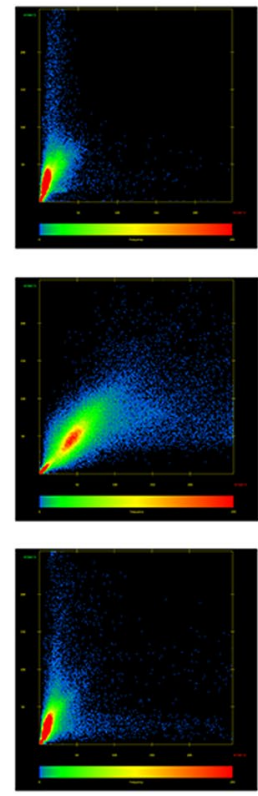

Figure 4. Quantification of $\gamma \mathrm{H} 2 \mathrm{AX}$ (A) and 53BP1 (B) in F1 embryos from males exposed to BPA during mitotic phase. Boxes represent median of around 200 cell of 5 embryos per treatment $(n=5)$. Asterisks indicate significant differences $(* * \mathrm{p}<0.01 ; * * \mathrm{p}<0.001)$ when comparing to control group. Representative images of $3.3 \mathrm{hpf}$-embryo at $5 \mathrm{X}$ (scale bar $=50 \mu \mathrm{m})$ appeared in $(\mathrm{C})$. Channels were both separated in blue (DAPI), red (Alexa Fluor 568) and green (Alexa Fluor 488) and merged. The graphic represents the co-localization of red channel $(\gamma \mathrm{H} 2 \mathrm{AX})$ in $\mathrm{X}$-axis and green channel (53BP1) in Y-axis.

males treated with $100 \mu \mathrm{g} / \mathrm{L}$ BPA showed less than $10 \%$ of DNA fragmentation). In contrast, in males exposed to $2000 \mu \mathrm{g} / \mathrm{L}$ BPA sperm DNA fragmentation is much higher, $27 \%$ of cells having between 40 and $50 \%$ of fragmented DNA. Single strand breaks in sperm are further transformed in double strand breaks in the embryos during replication ${ }^{48}$. DSBs induce the recruitment of many DNA damage response (DDR) proteins such as the sensor $\gamma \mathrm{H} 2 \mathrm{AX}$ (phosphorylated H2AX) and the mediator 53BP1 (p53-binding protein) ${ }^{49,50}$. This is in accordance with the ability of those embryos to initiate DNA repair: progeny from males exposed to $100 \mu \mathrm{g} / \mathrm{L}$ BPA showed higher levels of $\gamma \mathrm{H} 2 \mathrm{AX}$ and 53BP1, both proteins co-localizing for repairing foci generation. Similar responses to deal with DNA fragmentation were observed by our group in 3.3hpf-embryo obtained from sperm treated with UV during 30 and $40 \mathrm{~s}^{25}$. However, the scenario observed in embryos from males exposed to the highest dose of BPA was completely different: due to the great deal of sperm DNA fragmentation, no repairing potential was observed in the progeny.

The effects are more severe after BPA treatment during the whole spermatogenesis, embryo mortality overtaking $90 \%$ in batches from males exposed to $100 \mu \mathrm{g} / \mathrm{L} \mathrm{BPA}$ and reaching $100 \%$ two days after fertilization when fathers were exposed to $2000 \mu \mathrm{g} / \mathrm{L}$ BPA. This considerable boost in embryonic death is again closely related to the sperm DNA fragmentation, which highly increases in males treated with the toxicant during the whole spermatogenesis. After the treatment with $100 \mu \mathrm{g} / \mathrm{L}$ BPA only $30 \%$ of spermatozoa had less than $10 \%$ of fragmented DNA, whereas all the cells from males exposed to $2000 \mu \mathrm{g} / \mathrm{L}$ BPA exhibited DNA fragmentation higher than $40 \%$; $29 \%$ of them having between 70 and $80 \%$ of fragmented DNA. Both, meiosis and spermiogenesis, imply DNA strand breaks allowing the chromosome crosslinks during pachytene and the chromatin compaction during spermiogenesis ${ }^{51}$, therefore they arise as sensitive phases to BPA genotoxic damage. BPA has been already described 
A

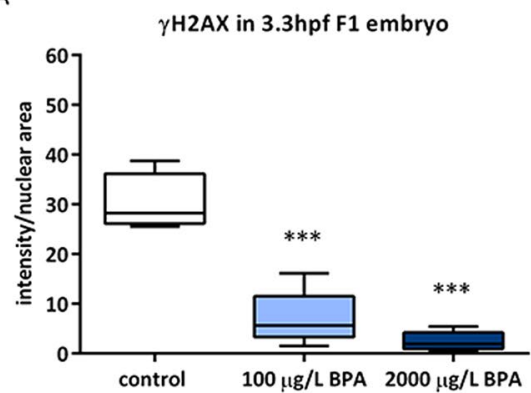

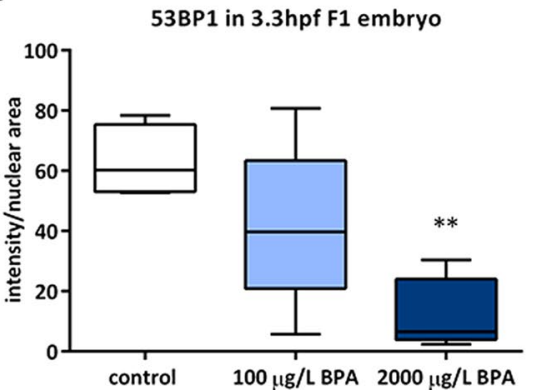

C

DAPI
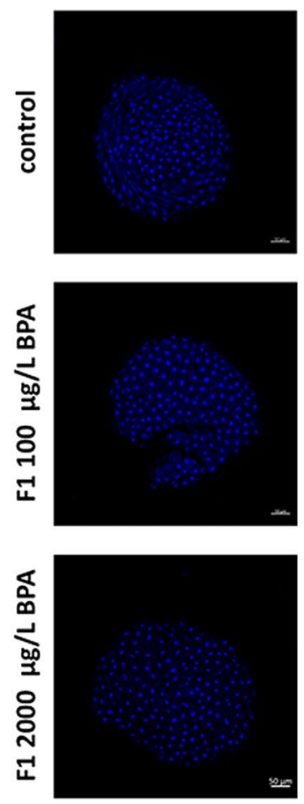

YH2AX
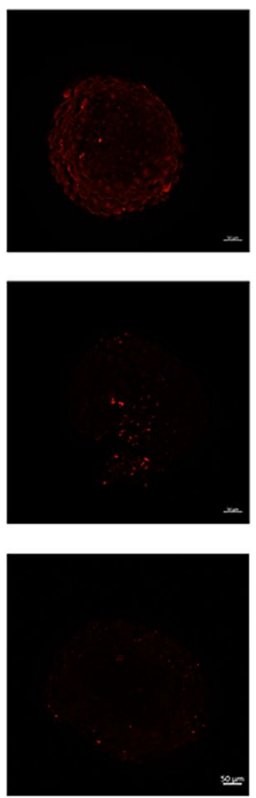

53BP1
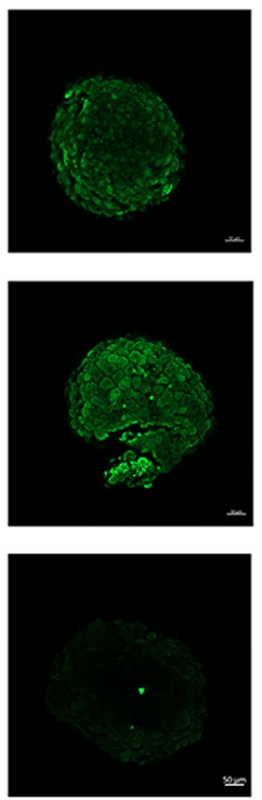

merged
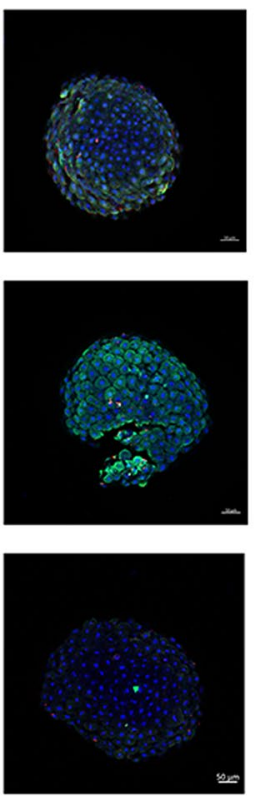

repairing foci
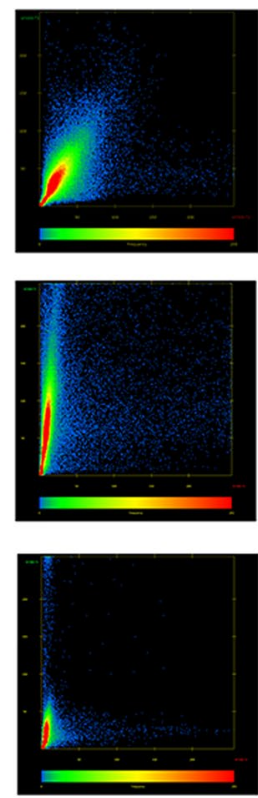

Figure 5. Quantification of $\gamma \mathrm{H} 2 \mathrm{AX}$ (A) and 53BP1 (B) in F1 embryo from males exposed to BPA during all the spermatogenesis. Boxes represent median of around 200 cell of 5 batches per treatment and timing $(\mathrm{n}=5)$. Asterisks indicate significant differences $(* * \mathrm{p}<0.01 ; * * \mathrm{p}<0.001)$ when comparing to control group. Representative images of $3.3 \mathrm{hpf}$-embryo at $5 \mathrm{X}$ (scale bar $=50 \mu \mathrm{m})$ appeared in $(\mathbf{C})$. Channels were both separated in blue (DAPI), red (Alexa Fluor 568) and green (Alexa Fluor 488) and merged. The graphic represents the co-localization of red channel $(\gamma \mathrm{H} 2 \mathrm{AX})$ in $\mathrm{X}$-axis and green channel (53BP1) in Y-axis.

to increase meiotic DNA strand breaks in pachytene spermatocytes, triggering meiotic disruption in rat ${ }^{20}$. The induced DNA damage will be transmitted unrepaired by the sperm to the zygote, as it has been reported in mammal and fish studies ${ }^{25,52}$. Analysis of the repairing ability showed a significant decrease in $\gamma \mathrm{H} 2 \mathrm{AX}$ on embryos from males treated with both doses of BPA and also in 53BP1 on embryos from males exposed to the highest dose of BPA. Phosphorylation of H2AX together with 53BP1 have been considered as biomarkers for DDR ${ }^{53}$, so our results showed that F1 embryos from males exposed to BPA during all the spermatogenesis were not able to face genomic fragmentation of the sperm.

Bearing in mind that paternal DNA damage is basically repaired in the zygote during early development ${ }^{22,54}$, and that zebrafish $3.3 \mathrm{hpf}$-embryos obtained with a certain degree of sperm DNA damage show an intense repairing activity ${ }^{25}$, the failure of repairing activity observed in the offspring likely leads to the activation of apoptosis ${ }^{55}$. Indeed, this mechanism represents a cell fate described to face unrepaired DNA fragmentation ${ }^{24}$. DNA repair was only accomplished in batches from males treated with the lowest doses of BPA during the mitotic phase, which showed basal levels of apoptosis. In contrast, the rest of the treatments causing high levels of sperm DNA damage led to embryonic inability to activate neither DNA damage signaling nor DNA repair, promoting an increased apoptotic activity. A similar apoptotic pattern was reported by our group in $8 \mathrm{hpf}$-embryo obtained from sperm with $40 \%$ DNA in tail, who also showed lower levels of $\gamma \mathrm{H} 2 \mathrm{AX}$ and, therefore, an absence of DNA repairing ability ${ }^{25}$ when the damage overcame the embryo repair capacity. Interestingly, Kao and colleagues ${ }^{56}$ reported that repair factors, such as 53BP1, are stabilized by a histone deacetylase (HDAC4), thus silencing of HDAC4 results in decreased 53BP1 protein level. Hence, the maintenance of 53BP1 levels in the progeny of males exposed to 
A

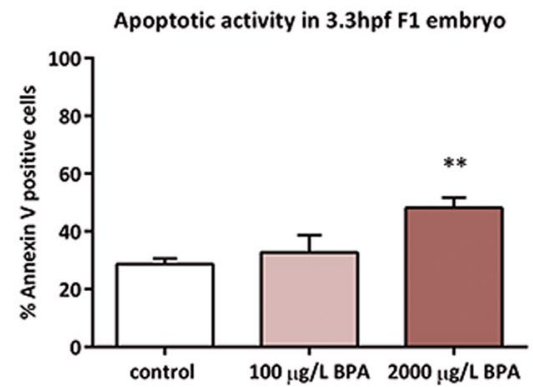

C

$$
\text { CONTROL }
$$
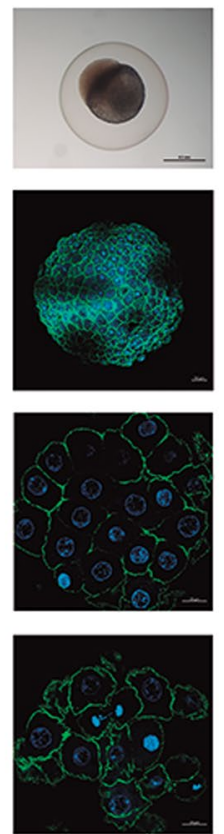

$100 \mu \mathrm{g} / \mathrm{L} \mathrm{BPA}$
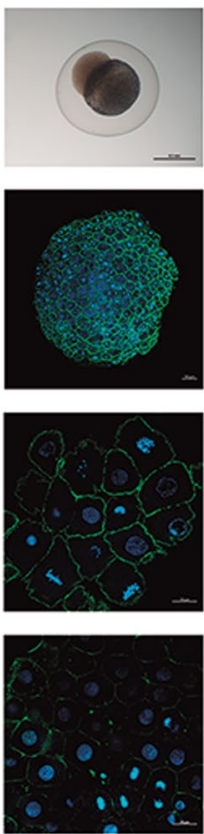

$2000 \mu \mathrm{g} / \mathrm{L} B P A$
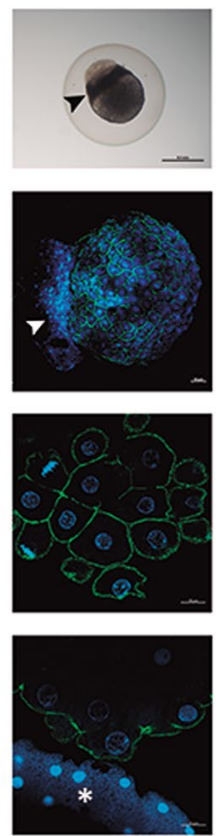

B

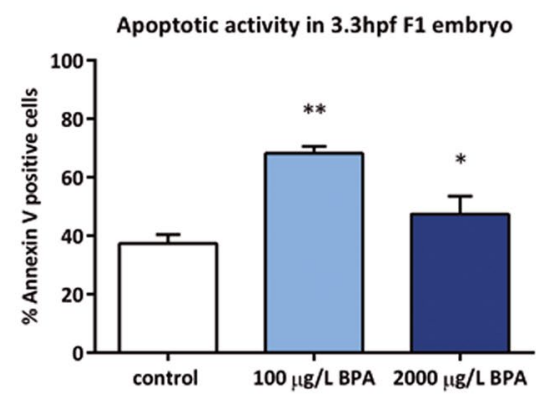

D CONTROL
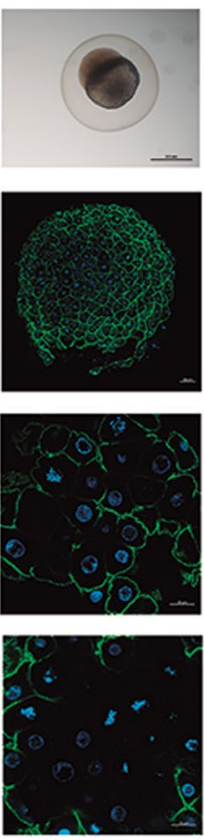

$2000 \mu \mathrm{g} / \mathrm{L}$ BPA
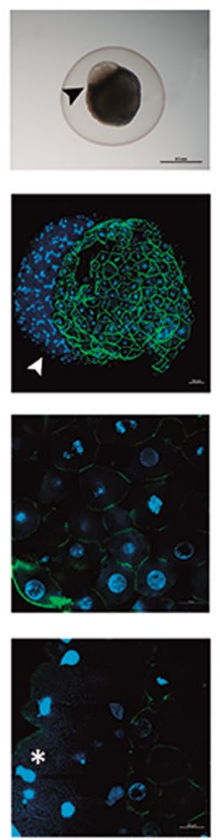
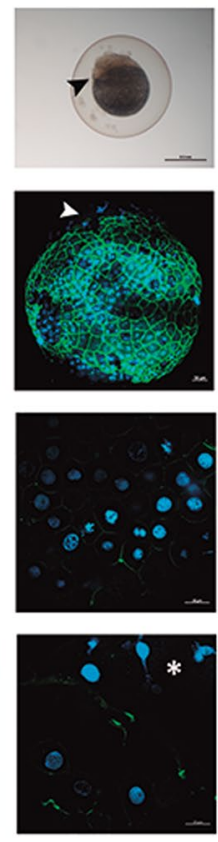

Figure 6. Assessment of apoptotic activity in: embryos from control males and males exposed to BPA during 2 weeks (A) and from males exposed to BPA during 3 weeks. Bars represents mean of 20,000 cells (20 embryos at 3.3hpf) of 4 different embryo batches per treatment $(n=4)(* p<0.05$; $* *<0.01)$. Representative images of 3.3hpf-embryo at light and confocal microscopy appeared in (C,D). For fluorescence images snaps were taken at $5 \mathrm{X}($ scale bar $=50 \mu \mathrm{m})$ and $40 \mathrm{X}($ scale bar $=50 \mu \mathrm{m})$ in both channels: blue for DAPI and green for Alexa Fluor 488 Phalloidin. Arrows point to hypertrophied YSL whereas asterisks highlight the presence of nuclei within the syncytium.

$100 \mu \mathrm{g} / \mathrm{L} \mathrm{BPA}$, in spite of their incapacity to form repairing foci, may be associated with the overexpression of hdac4 detected in these embryos.

Another mechanism involved in the DDR is orchestrated by Rho GTPases, since they control the accessibility of the chromatin for DNA repair and they allow the entrance of DDR factors to the nucleus by modifying actin cytoskeleton $^{57}$. Even though the analysis of actin cytoskeleton with phalloidin did not reveal any evident alteration of actin distribution in the blastomeres among treatments, it did allow the observation of dramatic changes in the formation of an extraembryonic tissue, known as yolk syncytial layer (YLS). The formation of YSL occurs at blastula stage due to the absence of cytokinesis, a process regulated by the same small GTPases of Rho family ${ }^{58}$ which is dependent of the reorganization of the actin cytoskeleton. YSL is crucial for organizing both endoderm and mesoderm, cardiac progenitors formation and regulation of larval metabolism ${ }^{59}$. Confocal imaging showed that embryos who were not able to repair DNA displayed hypertrophic YLS, similar to that produced when Rock (protein which binds to Rho GTPases) was inhibited ${ }^{58}$, suggesting that paternal BPA exposure causes embryonic dysregulation of this signaling pathway, which could also have an impact on DDR.

Besides genotoxic effects of BPA, epigenetic modifications triggered by this toxicant must also be considered. The first study concerning epigenotoxicity of BPA revealed that maternal exposure in mice induced a change in F1 coat coloration pattern due to a reduction in methylation of IAP (Intracisternal A-Particle) of Agouti gene promoter ${ }^{60}$. From this moment onwards, many investigations have confirmed that BPA is able to modify DNA methylation in both female ${ }^{61,62}$ and male germline $e^{21,35,36}$. However, in our previous study of paternal BPA 
A

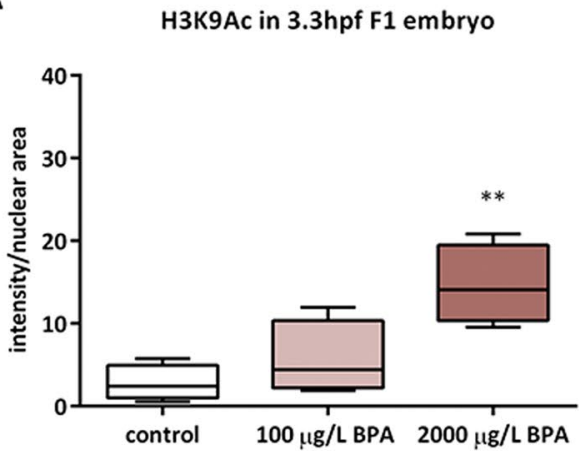

C

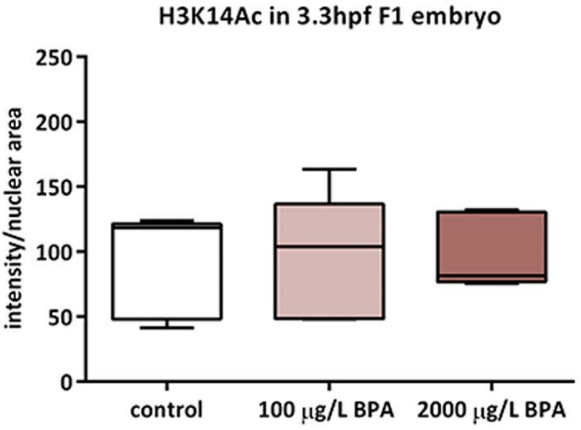

E

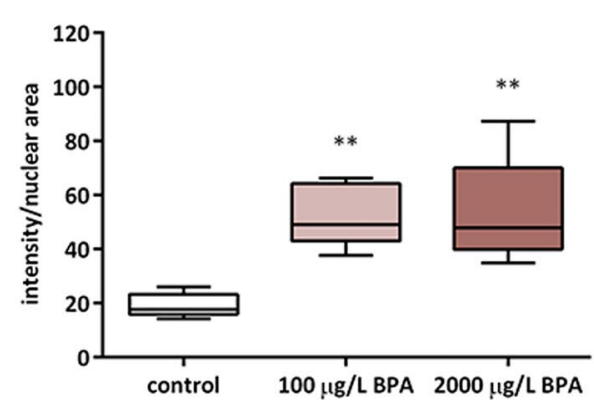

G

H4K12Ac in 3.3hpf F1 embryo

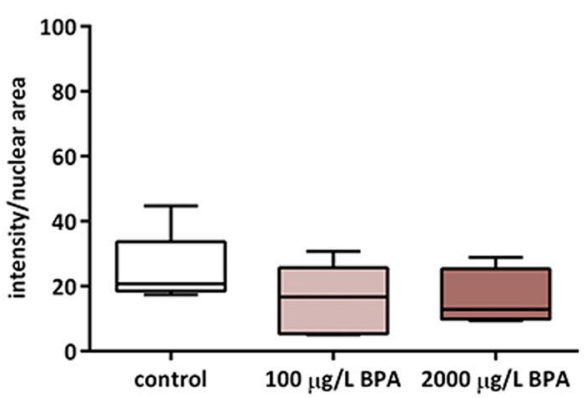

B

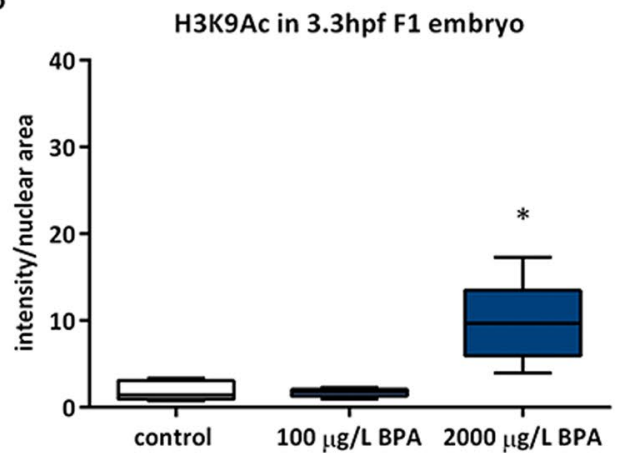

D

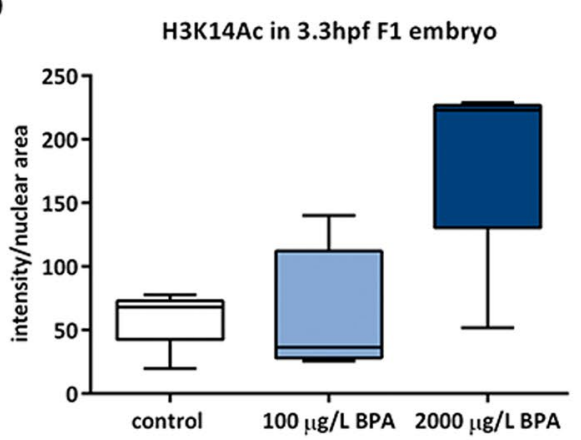

$\mathrm{F}$

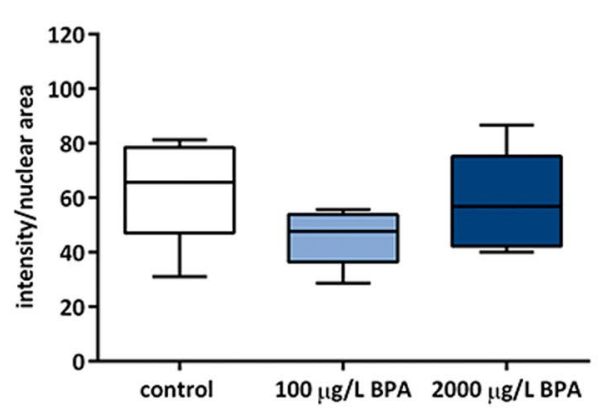

$\mathrm{H}$

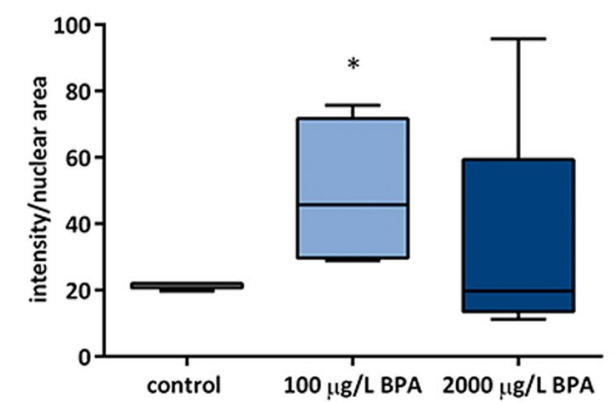

Figure 7. Analysis of several histone marks prone to acetylation: H3K9 (A,B), H3K14 (C,D), H3K27 (E,F) and $\mathrm{H} 4 \mathrm{~K} 12(\mathbf{G}, \mathbf{H})$ in embryo at $3.3 \mathrm{hpf}$ from males exposed to BPA during mitotic phase as well as the whole spermatogenesis, respectively. Boxes represent nuclear intensity of around 200 cell of 5 batches per treatment and timing $(\mathrm{n}=5)$. Asterisks indicate significant differences $(* \mathrm{p}<0.05 ; * \mathrm{p}<0.01)$ when comparing to control group.

exposure, during mitotic spermatogenesis, no alterations in global DNA methylation of sperm or testicular cells were found ${ }^{45}$. Neither did DNA methylation in the progeny from males exposed to BPA during different windows change, nor the expression of DNA-methyltransferases. In contrast to DNA methylation, BPA effects on histone acetylation have barely been studied. Recent results from our group have demonstrated that zebrafish 
A

epigenetic enzymes in $24 \mathrm{hpf} \mathrm{F1} \mathrm{embryo}$

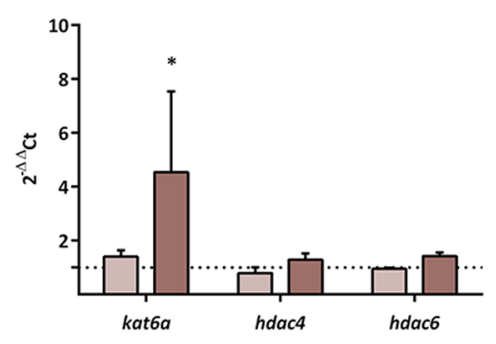

B

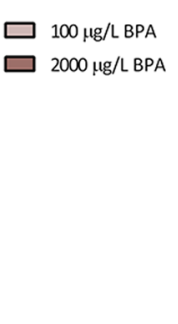

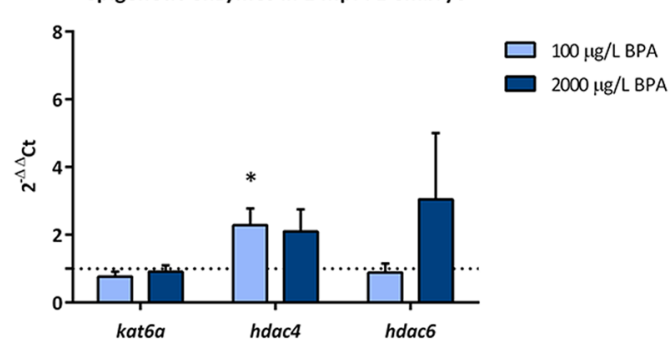

Figure 8. Evaluation of epigenetic enzymes expression in: 24hpf-embryo from males exposed to BPA only during mitotic phase $(\mathbf{A})$ and also meiotic phase and spermiogenesis $(\mathbf{B})$. Bars represent expression levels relative to $a c t b 2$, which were calculated using $2^{-\Delta \Delta C t}$ method of three independent experiments $(n=3)$. Asterisks indicate significant differences $(* \mathrm{p}<0.05)$ when comparing to control group (dashed line).

male exposure to the same doses of BPA (100 and $2000 \mu \mathrm{g} / \mathrm{L} \mathrm{BPA})$ triggered an increase in H3K9Ac, H3K14Ac and H4K12Ac in testicular cells ${ }^{21}$. However, Chen and colleagues ${ }^{38}$ reported a decrease in H3K9Ac, H3K27Ac and $\mathrm{H} 4 \mathrm{~K} 12 \mathrm{Ac}$ in rat testes after long term exposure to a low dose of BPA. In this work, the evaluation of histone modifications in spermatozoa showed an increase in H3K27Ac and H3K9Ac after two and three weeks of BPA exposure, respectively. Moreover, this marks were also more acetylated in the progeny of these males: H3K9Ac and $\mathrm{H} 3 \mathrm{~K} 27 \mathrm{Ac}$ were increased in embryo from males exposed to BPA during mitotic phase of spermatogenesis and $\mathrm{H} 3 \mathrm{~K} 9 \mathrm{Ac}$ and $\mathrm{H} 4 \mathrm{~K} 12 \mathrm{Ac}$ rose in embryo from males treated with BPA during the whole spermatogenesis. As a result of a continuous remodeling process, sperm epigenome becomes very susceptible to environmental factors and, when disrupted, may result in male infertility as well as in abnormal embryo development ${ }^{28,31}$. Specifically, histone modifications in sperm are of utmost importance for next generation development ${ }^{9}$. In fact, alterations of histone epigenetic marks in mature spermatozoa have been associated with abnormal embryo gene expression and phenotype $\mathrm{e}^{63-65}$. Our results showed that changes in sperm histone acetylation entailed similar changes in early embryos. The paternal transmission of these epigenetic alterations might be explained by changes in the expression of a histone acetyltransferase (kat6a).

In this study we have demonstrated that effects of male BPA exposure on sperm information and the consequences for the next generation strongly depend on the doses and on the period of spermatogenesis affected. Hence, exposure during the whole spermatogenesis leads to more sperm DNA damage than that caused by exposure only during mitotic phase. Due to this excessive fragmentation, the embryo capacity to activate the DNA repairing machinery is exceeded and, therefore, they initiate an apoptotic process. Our findings showed that paternal BPA exposure, even to $100 \mu \mathrm{g} / \mathrm{L}$ only during mitotic period, triggered modifications in sperm histone acetylation and, what is more, these epigenetic alterations were transmitted to the next generation, thus jeopardizing early embryo development. Hence, this work highlights the potential of environmentally-induced alterations to be inherited by future generations.

\section{Methods}

Ethics statement. This work is included in a project from the Spanish Ministry of Economy and Competitiveness (Project AGL2014-53167-C3-3-R) specifically approved by the University of León Bioethical Committee as well as by the competent body of Junta de Castilla y León (project number: ULE009-2016). All the animals were manipulated in accordance with the Guidelines of the European Union Council (86/609/EU, modified by 2010/62/EU), following Spanish regulations (RD 1201/2005, abrogated by RD 53/2013) for the use of laboratory animals.

Zebrafish maintenance. $\quad$ 8-month-old zebrafish, $\mathrm{AB}$ strain (wildtype), were maintained in $2.5 \mathrm{~L}$ aquaria (ZebTEC, Tecniplast System) with a recirculating water system ( $\mathrm{pH} 7.0-7.5,30 \mathrm{mg} / \mathrm{L} \mathrm{Instant} \mathrm{Ocean,} \mathrm{at} 27-29^{\circ} \mathrm{C}$, 14:10 light-dark cycle). Animals were fed twice a day with dry food (Special Diets Services).

BPA paternal exposure. The adult zebrafish males ( 4 fishes per replicate) were exposed to vehicle (ethanol $0.014 \%(\mathrm{v} / \mathrm{v}))$ and two doses of BPA previously tested by our group ${ }^{45}: 100$ and $2000 \mu \mathrm{g} / \mathrm{L}(0.44 \mu \mathrm{M}$ and $8.8 \mu \mathrm{M}$, respectively) in $1.5 \mathrm{~L}$ of zebrafish water. More than 20 replicates per treatment were performed to obtain all the required samples. The tolerable daily intake (TDI) of BPA has been established by the EFSA in $4 \mu \mathrm{g} / \mathrm{kg}$ weight/day for humans $s^{64}$. In comparison with these values, the doses used in this work are high. However, taking into account the health policy and the environmental concentrations, $100 \mu \mathrm{g} / \mathrm{L}$ BPA was established as the total allowed concentration in drinking water by the Environmental Protection Agency (EPA) in $2008^{66}$, whereas $2000 \mu \mathrm{g} / \mathrm{L} \mathrm{BPA}$ fits in the normal levels of BPA on waste landfill leachates ${ }^{67}$. Moreover, the EPA recommends setting the highest dose level at the maximum tolerated dose (MTD). Based on the guidelines of aquatic tests, MTC is approximately one third of the fish acute $96-\mathrm{h} \mathrm{LC}_{50}$ (the dose inducing 50\% mortality at $96 \mathrm{hpf}$ ). In zebrafish, this dose has been established in $12 \mathrm{mg} / \mathrm{L}^{68}$, so we are still below half the highest recommended dose, that would be $4 \mathrm{mg} / \mathrm{L}$. Given that zebrafish spermatogenesis has been estimated to last around 21 days ${ }^{10}$ and meiotic and spermiogenic phases to last 6 days ${ }^{42}$, fishes were subjected to BPA exposure during two different periods: one affecting mitotic phase 
-2 weeks, short exposure- and another one affecting also meiosis and spermiogenesis -3 weeks, long exposure(Supplemental Material, Fig. S1).

Comet assay in spermatozoa. 4 samples of pooled sperm from 4 control or 4 BPA-exposed males each, were obtained by abdominal massage and diluted in PBS to a final concentration of around $10^{6}$ cells $/ \mathrm{mL}$. In order to assess DNA fragmentation, Single Cell Gel Electrophoresis (SCGE) was performed as described by Fernández-Díez and colleagues ${ }^{25}$. Sperm cells were mixed with $0.5 \%$ low melting point agarose and $75 \mu \mathrm{L}$ of cell suspension were spread out on ATE ([3-aminopropyl]trimethoxysilane) coated slides with a glass coverslip. Once they have solidified, coverslips were removed and slides were incubated $1 \mathrm{~h}$ at $4{ }^{\circ} \mathrm{C}$ in lysis solution $(100 \mathrm{mM}$ EDTA- $\mathrm{Na}_{2}, 2.5 \mathrm{M} \mathrm{NaCl}, 10 \mathrm{mM}$ Tris- $\mathrm{HCl}$ and $1 \%$ Triton $\left.\mathrm{X}-100, \mathrm{pH} 10\right)$. Then, they were placed into an electrophoresis buffer ( $1 \mathrm{mM}$ EDTA- $\mathrm{Na}_{2}, 0.3 \mathrm{M} \mathrm{NaOH}, \mathrm{pH} 13$ ) for $20 \mathrm{~min}$ to promote the DNA unwind followed by $20 \mathrm{~min}$ of electrophoresis $(25 \mathrm{~V}, 280-350 \mathrm{~mA})$. The slides were washed using a neutralizing solution $(0.4 \mathrm{M} \mathrm{Tris}-\mathrm{HCl}$, $\mathrm{pH} 7.5$ ). Cells were fixed with methanol and nuclei were stained with $0.5 \mu \mathrm{g} / \mathrm{mL} 4^{\prime}$, 6-diamidino-2-phenylindole (DAPI). 50 images per replicate (4 in each treatment) were analysed with CaspLab software (1.2.3beta2; http:// www.casp.of.pl.), the percentage of tail DNA (\% DNAt) being used as a measure of DNA fragmentation.

Immunostaining of epigenetic marks in spermatozoa. Sperm from control and BPA-exposed males was collected as indicated above. Samples were fixed with $4 \%$ (wt/vol) paraformaldehyde for 20 min at room temperature and washed twice with bi-distilled water. $25 \mu \mathrm{l}$ of spermatozoa from each individual male (4 males per treatment and period of exposure) were spread out on ATE coated slides at $37^{\circ} \mathrm{C}$ overnight. Following steps were done using the method described by González-Rojo and co-workers ${ }^{69}$. Primary antibodies and working dilutions are indicated in Supplemental Material, Table S1. Slides were mounted with ProLong Gold Antifade Mountant (Thermo Scientific) and observed under confocal microscope LSM 800 (Zeiss). Relative quantity of each mark was quantified in around 200 cells per sample using ImageJ software.

Embryo collection and mortality. So as to obtain the embryos, control and exposed males were mated with non-treated females according to a sex ratio $1: 2$. Embryos were immediately rinsed $2 \mathrm{~min}$ in $0.5 \%(\mathrm{vol} / \mathrm{vol})$ bleach and $10 \mathrm{~s}$ in $70 \%$ (vol/vol) ethanol. Then, they were transferred to egg water containing $0.038 \mathrm{mM} \mathrm{CaCO}_{3}$, $0.446 \mathrm{mM} \mathrm{NaHCO}, 1.025 \mathrm{mM}$ sea salt and $0.005 \%$ (vol/vol) methylene blue and kept at $28^{\circ} \mathrm{C}$ until further analysis. Embryo mortality was evaluated from $24 \mathrm{hpf}$ (hours post fertilization) each day until they reached $120 \mathrm{hpf}$.

Gene expression analysis in embryo. Each RNA sample was extracted from 30 embryos per batch obtained from control and BPA-exposed males (3.3 hpf and $24 \mathrm{hpf}$ ) using Trizol reagent (Invitrogen, Spain) according to the manufacturer's protocol. The concentration and purity (A260/A280 $=2.2-2$ ) of RNA samples was measured using the NanoDrop ND-1000 UV-Vis Spectrophotometer (Thermo Scientific), whereas the integrity was assessed by electrophoresis on agarose gel. For cDNA syntheses and RT-qPCR, the same protocols and primer sequences for DNA methyltransferases (dnmt1, dnmt3, dnmt5, dnmt8), histone acetyltransferase (kat6a) and histone deacetylases ( $h d a c 4$ and $h d a c 6$ ) as those previously described by our group ${ }^{70}$ were used.

Embryonic whole mount immunostaining. Embryos at $3.3 \mathrm{hpf}$, obtained from control and treated males, were fixed in $4 \%(\mathrm{wt} / \mathrm{vol})$ paraformaldehyde overnight at $4{ }^{\circ} \mathrm{C}$. After washing twice in PBS $(8.37 \mathrm{mM}$ $\mathrm{Na}_{2} \mathrm{HPO}_{4}, 1.83 \mathrm{mM} \mathrm{KH}_{2} \mathrm{PO}_{4}, 149.9 \mathrm{mM} \mathrm{NaCl}, \mathrm{pH}$ 7.4) and removing both chorion and yolk sac, cells were permeabilised with methanol 2 hours at $-20^{\circ} \mathrm{C}$. For $5 \mathrm{mC}$ and $\gamma \mathrm{H} 2 \mathrm{AX} / 53 \mathrm{BP} 1$ analysis, an extra step of $2 \mathrm{~h}$ DNA denaturalization with $2 \mathrm{~N} \mathrm{HCl}$ was performed. Then, all embryos were washed 3 times with TBS-T $1 \%$ (vol/ vol) and transferred to blocking solution (3\% (wt/vol) BSA in TBS-T 1\%) for $2 \mathrm{~h}$ at room temperature. Embryos were incubated for 2 days at $4{ }^{\circ} \mathrm{C}$ in blocking solution with the primary antibodies described in Supplemental Material, Table S1. Next, they were rinsed in fluorescence-conjugated secondary antibodies (goat anti-mouse AlexaFluor 568 and goat anti-rabbit AlexaFluor 488 (Invitrogen)) at $4{ }^{\circ} \mathrm{C}$ overnight. For fluorescent labelling of actin, embryos were fixed as described above and directly rinsed in PBS-T $2 \%$ (vol/vol) for $2 \mathrm{~h}$. Then, they were incubated with Alexa Fluor 488 Phalloidin for $1 \mathrm{~h}$. Eventually, nuclei were stained with $180 \mu \mathrm{M}$ DAPI for $8 \mathrm{~min}$. Whole embryos were mounted with ProLong Gold Antifade Mountant (Thermo Scientific) and observed under confocal microscope LSM 800 (Zeiss) using ibidi. Relative quantity of each mark was quantified using ImageJ software.

Apoptotic activity. $\quad 20$ embryos per batch from control and BPA-exposed males were collected at $3.3 \mathrm{hpf}$ and they were dechorionized. Blastomeres were washed with PBS, transferred to a tube and centrifuged at $1000 \mathrm{xg}$ $5 \mathrm{~min}$ at $4^{\circ} \mathrm{C}$. Pellets were re-suspended in annexin buffer to perform the indicated protocol (FITC annexin V Apoptosis Detection Kit (Molecular Probes by Life Technologies)). Cells (20,000 events per sample) were analyzed by flow cytometry (MACSQuant Analyzer 10) and apoptotic activity was established as percentage of annexin V-positive cells.

Statistical analyses. Statistical analyses were performed with SPSS version 24.0 (IBM). The normality of the data was tested by the Shapiro-Wilk's test. For non-parametric data, a Kruskal-Wallis test was performed using Dunn's post hoc test $(\mathrm{p}<0.05)$. For parametric data, an analysis of variance (ANOVA) with a DMS post hoc test was carried out $(\mathrm{p}<0.05)$. All data in bars are represented as mean $\pm S E M$, whereas boxes represent median \pm maximum and minimum.

Received: 4 June 2019; Accepted: 12 November 2019;

Published online: 02 December 2019 


\section{References}

1. Erler, C. \& Novak, J. Bisphenol a exposure: Human risk and health policy. J. Pediatr. Nurs. 25, 400-407 (2010).

2. Vogel, S. A. The politics of plastics: the making and unmaking of bisphenol a 'safety'. Am. J. Public Health 99(Suppl 3), 559-566 (2009).

3. Acconcia, F., Pallottini, V. \& Marino, M. Molecular mechanisms of action of BPA. Dose-Response 13, 1-9 (2015).

4. Jenardhanan, P., Panneerselvam, M. \& Mathur, P. P. Effect of environmental contaminants on spermatogenesis. Seminars in Cell and Developmental Biology 59, 126-140 (2016).

5. Lan, S. et al. Neonatal bisphenol A exposure induces meiotic arrest and apoptosis of spermatogenic cells. Oncotarget 7, 10606-10615 (2016).

6. Crain, D. A. et al. An ecological assessment of bisphenol-A: Evidence from comparative biology. Reprod. Toxicol. 24, 225-239 (2007).

7. MacKay, H. \& Abizaid, A. A plurality of molecular targets: The receptor ecosystem for bisphenol-A (BPA). Horm. Behav. 101, 59-67 (2018).

8. Almeida, S., Raposo, A., Almeida-González, M., Carrascosa, C. \& Bisphenol, A. Food Exposure and Impact on Human Health. Compr. Rev. Food Sci. Food Saf. 17, 1503-1517 (2018).

9. Soubry, A., Hoyo, C., Jirtle, R. L. \& Murphy, S. K. A paternal environmental legacy: evidence for epigenetic inheritance through the male germ line. Bioessays 36, 359-71 (2014).

10. Schulz, R. W. et al. Spermatogenesis in fish. Gen. Comp. Endocrinol. 165, 390-411 (2010).

11. Morais, R. D. V. S. et al. Thyroid hormone stimulates the proliferation of sertoli cells and single type A spermatogonia in adult zebrafish (Danio rerio) testis. Endocrinology 154, 4365-4376 (2013).

12. Li, M. W. M., Mruk, D. D., Lee, W. M. \& Cheng, C. Y. Disruption of the blood-testis barrier integrity by bisphenol A in vitro: is this a suitable model for studying blood-testis barrier dynamics? Int. J. Biochem. Cell Biol. 41, 2302-14 (2009).

13. Manfo, F. P. T., Jubendradass, R., Nantia, E. A., Moundipa, P. F. \& Mathur, P. Adverse effects of bisphenol a on male reproductive function. Rev. Environ. Contam. Toxicol. 228, 57-82 (2014).

14. Mathur, P. P. \& D'Cruz, S. C. The effect of environmental contaminants on testicular function. Asian Journal of Andrology 13, 585-591 (2011).

15. Mínguez-Alarcón, L., Hauser, R. \& Gaskins, A. J. Effects of bisphenol A on male and couple reproductive health: a review. Fertil. Steril. 106, 864-870 (2016).

16. McCarrey, J. R. Distinctions between transgenerational and non-transgenerational epimutations. Mol. Cell. Endocrinol. 398, 13-23 (2014).

17. Allard, P. \& Colaiacovo, M. P. Bisphenol A impairs the double-strand break repair machinery in the germline and causes chromosome abnormalities. Proc. Natl. Acad. Sci. 107, 20405-20410 (2010).

18. Brieño-Enríquez, M. A. et al. Human meiotic progression and recombination are affected by Bisphenol A exposure during in vitro human oocyte development. Hum. Reprod. 26, 2807-2818 (2011).

19. Ikhlas, S., Usman, A. \& Ahmad, M. In vitro study to evaluate the cytotoxicity of BPA analogues based on their oxidative and genotoxic potential using human peripheral blood cells. Toxicol. Vitr. 60, 229-236 (2019).

20. Liu, C. et al. Exposure to bisphenol A disrupts meiotic progression during spermatogenesis in adult rats through estrogen-like activity. Cell Death Dis. 4, (2013).

21. González-Rojo, S., Lombó, M., Fernández-Díez, C. \& Herráez, M. P. Male exposure to bisphenol a impairs spermatogenesis and triggers histone hyperacetylation in zebrafish testes. Environ. Pollut. 248, 368-379 (2019).

22. Jaroudi, S. et al. Expression profiling of DNA repair genes in human oocytes and blastocysts using microarrays. Hum. Reprod. 24, 2649-2655 (2009).

23. Jaroudi, S. \& SenGupta, S. DNA repair in mammalian embryos. Mutation Research - Reviews in Mutation Research 635, 53-77 (2007).

24. González-Marín, C., Gosálvez, J. \& Roy, R. Types, causes, detection and repair of DNA fragmentation in animal and human sperm cells. Int. J. Mol. Sci. 13, 14026-14052 (2012).

25. Fernández-Díez, C., González-Rojo, S., Lombó, M. \& Herráez, M. P. Tolerance to paternal genotoxic damage promotes survival during embryo development in zebrafish (Danio rerio). Biol. Open 7, bio030130 (2018).

26. Marchetti, F., Bishop, J. B., Cosentino, L., Moore, D. \& Wyrobek, A. J. Paternally Transmitted Chromosomal Aberrations in Mouse Zygotes Determine Their Embryonic Fate1. Biol. Reprod. 70, 616-624 (2004).

27. Zheng, W.-W. et al. Sperm DNA damage has a negative effect on early embryonic development following in vitro fertilization. Asian J. Androl. 20, 75-79 (2018).

28. Champroux, A., Cocquet, J., Henry-Berger, J., Drevet, J. R. \& Kocer, A. A Decade of Exploring the Mammalian Sperm Epigenome: Paternal Epigenetic and Transgenerational Inheritance. Front. Cell Dev. Biol. 6, 50 (2018).

29. Herráez, M. P. et al. Paternal contribution to development: Sperm genetic damage and repair in fish. Aquaculture 472, 45-59 (2017).

30. Kumar, M., Kumar, K., Jain, S., Hassan, T. \& Dada, R. Novel insights into the genetic and epigenetic paternal contribution to the human embryo, https://doi.org/10.6061/clinics/2013(Sup01)02

31. Carrell, D. T. \& Hammoud, S. S. The human sperm epigenome and its potential role in embryonic development. Molecular Human Reproduction, https://doi.org/10.1093/molehr/gap090 (2009).

32. Estill, M. S. \& Krawetz, S. A. The Epigenetic Consequences of Paternal Exposure to Environmental Contaminants and Reproductive Toxicants. Curr. Environ. Heal. reports 3, 202-213 (2016).

33. Dada, R., et al Epigenetics and its Role in Male Infertility. In Handbook of Fertility: Nutrition, Diet, Lifestyle and Reproductive Health 213-223, https://doi.org/10.1016/B978-0-12-800872-0.00036-6 (2012).

34. Mileva, G., Baker, S. L., Konkle, A. T. M. \& Bielajew, C. Bisphenol-A: Epigenetic reprogramming and effects on reproduction and behavior. International Journal of Environmental Research and Public Health, https://doi.org/10.3390/ijerph110707537 (2014).

35. Miao, M. et al. LINE-1 hypomethylation in spermatozoa is associated with Bisphenol A exposure. Andrology, https://doi. org/10.1111/j.2047-2927.2013.00166.x (2014).

36. Laing, L. V. et al. Bisphenol A causes reproductive toxicity, decreases dnmt1 transcription, and reduces global DNA methylation in breeding zebrafish (Danio rerio). Epigenetics, https://doi.org/10.1080/15592294.2016.1182272 (2016).

37. Yin, L. et al. Role of DNA methylation in bisphenol A exposed mouse spermatocyte. Environ. Toxicol. Pharmacol. 48, 265-271 (2016).

38. Chen, Z. et al. Long-term exposure to a a€safe' dose of bisphenol A reduced protein acetylation in adult rat testes. Sci. Rep. 7, 1-9 (2017).

39. Skinner, M. K. Endocrine disruptor induction of epigenetic transgenerational inheritance of disease. Mol. Cell. Endocrinol. 398, 4-12 (2014).

40. Xin, F., Susiarjo, M. \& Bartolomei, M. S. Multigenerational and transgenerational effects of endocrine disrupting chemicals: A role for altered epigenetic regulation? Seminars in Cell and Developmental Biology 43, 66-75 (2015).

41. Klosin, A., Casas, E., Hidalgo-Carcedo, C., Vavouri, T. \& Lehner, B. Transgenerational transmission of environmental information in C. elegans. Science (80-.). 356, 320-323 (2017)

42. Leal, M. C. et al. Histological and Stereological Evaluation of Zebrafish (Danio rerio) Spermatogenesis with an Emphasis on Spermatogonial Generations1. Biol. Reprod. 81, 177-187 (2009). 
43. Kimmel, C. B., Ballard, W. W., Kimmel, S. R., Ullmann, B. \& Schilling, T. F. Stages of embryonic development of the zebrafish. Dev. Dyn. 203, 253-310 (1995).

44. Santos, R. et al. Parental exposure to methyl methane sulfonate of three-spined stickleback: contribution of DNA damage in male and female germ cells to further development impairment in progeny. Ecotoxicology 22, 815-24 (2013).

45. Lombó, M. et al. Transgenerational inheritance of heart disorders caused by paternal bisphenol A exposure. Environ. Pollut. 206, 667-678 (2015).

46. Ribas-Maynou, J. \& Benet, J. Single and Double Strand Sperm DNA Damage: Different Reproductive Effects on Male Fertility. Genes (Basel). 10, 105 (2019).

47. Labbé, C., Robles, V. \& Herraez, M. P. Epigenetics in fish gametes and early embryo. Aquaculture 472, 93-106 (2017),

48. Simon, L. et al. Paternal influence of sperm DNA integrity on early embryonic development. Hum. Reprod. 29, 2402-2412 (2014).

49. Podhorecka, M., Skladanowski, A. \& Bozko, P. H2AX phosphorylation: Its role in DNA damage response and cancer therapy. J. Nucleic Acids 2010 (2010).

50. Yoshiyama, K., Sakaguchi, K. \& Kimura, S. DNA Damage Response in Plants: Conserved and Variable Response Compared to Animals. Biology (Basel). 2, (1338-1356 (2013).

51. Rathke, C., Baarends, W. M., Awe, S. \& Renkawitz-Pohl, R. Chromatin dynamics during spermiogenesis. Biochim. Biophys. Acta Gene Regul. Mech. 1839, 155-168 (2014).

52. Marchetti, F., Bishop, J., Gingerich, J. \& Wyrobek, A. J. Meiotic interstrand DNA damage escapes paternal repair and causes chromosomal aberrations in the zygote by maternal misrepair. Sci. Rep. 5, 1-7 (2015).

53. Mariotti, L. G. et al. Use of the $\gamma-\mathrm{H} 2 \mathrm{AX}$ assay to investigate DNA repair dynamics following multiple radiation exposures. PLoS One 8, 79541 (2013).

54. Derijck, A., Van der heijden, G., Giele, M., Philippens, M. \& De boer, P. DNA double-strand break repair in parental chromatin of mouse zygotes, the first cell cycle as an origin of de novo mutation. Hum. Mol. Genet. 17, 1922-1937 (2008).

55. Hakem, R. DNA-damage repair; the good, the bad, and the ugly. EMBO J. 27, 589-605 (2008).

56. Kao, G. D. et al. Histone deacetylase 4 interacts with 53BP1 to mediate the DNA damage response. J. Cell Biol. 160, 1017-1027 (2003).

57. Fritz, G. \& Henninger, C. Rho gtpases: Novel players in the regulation of the DNA damage response? Biomolecules 5, 2417-2434 (2015).

58. Chu, L.-T. et al. Yolk syncytial layer formation is a failure of cytokinesis mediated by Rock1 function in the early zebrafish embryo. Biol. Open 1, 747-753 (2012).

59. Carvalho, L. \& Heisenberg, C. P. The yolk syncytial layer in early zebrafish development. Trends Cell Biol. 20, 586-592 (2010).

60. Dolinoy, D. C., Huang, D. \& Jirtle, R. L. Maternal nutrient supplementation counteracts bisphenol A-induced DNA hypomethylation in early development. Proc. Natl. Acad. Sci. 104, 13056-13061 (2007).

61. Chao, H. H. et al. Bisphenol A exposure modifies methylation of imprinted genes in mouse oocytes via the estrogen receptor signaling pathway. Histochem. Cell Biol. 137, 249-259 (2012).

62. Santangeli, S., Consales, C., Pacchierotti, F., Habibi, H. \& Carnevali, O. Transgenerational effects of BPA on female reproduction. Sci. Total Environ., https://doi.org/10.1016/j.scitotenv.2019.06.029 (2019).

63. Siklenka, K. et al. Disruption of histone methylation in developing sperm impairs offspring health transgenerationally. Science (80-.). 350, aab2006-aab2006 (2015).

64. Pérez-Cerezales, S. et al. Elimination of methylation marks at lysines 4 and 9 of histone 3 (H3K4 and H3K9) of spermatozoa alters offspring phenotype. Reprod. Fertil. Dev. 29, 740-746 (2017).

65. Klosin, A. et al.Transgenerational transmission of environmental information in C. elegans. Science 356, 320-323 (2017).

66. Willhite, C. C., Ball, G. L. \& McLellan, C. J. Derivation of a bisphenol a oral reference dose (RfD) and drinking-water equivalent concentration. J. Toxicol. Environ. Heal. - Part B Crit. Rev. 11, 69-146 (2008).

67. Wilk, B. K., Fudala-Ksiazek, S., Szopińska, M. \& Luczkiewicz, A. Landfill leachates and wastewater of maritime origin as possible sources of endocrine disruptors in municipal wastewater. Environ. Sci. Pollut. Res., https://doi.org/10.1007/s11356-019-05566-4 (2019).

68. Moreman, J. et al. Acute toxicity, teratogenic and estrogenic effects of Bisphenol A and its alternative replacements Bisphenol S, Bisphenol F and Bisphenol AF in zebrafish embryo-larvae. Environ. Sci. Technol. acs.est.7b03283, https://doi.org/10.1021/acs. est.7b03283 (2017).

69. González-Rojo, S., Fernández-Díez, C., Lombó, M. \& Herráez, M. P. Distribution of DNA damage in the sperm nucleus: A study of zebrafish as a model of histone-packaged chromatin. Theriogenology 122, 109-115 (2018).

70. Lombó, M., González-Rojo, S., Fernández-Díez, C. \& Herráez, M. P. Cardiogenesis impairment promoted by bisphenol A exposure is successfully counteracted by epigallocatechin gallate. Environ. Pollut. 246, 1008-1019 (2019).

\section{Acknowledgements}

This work was funded by the Spanish Ministry of Economy and Competitiveness (Project AGL2014-53167-C33-R; PhD Grant BES-2015-071885).

\section{Author contributions}

M.L. carried out the fish exposure, obtained and analysed the samples, interpreted the data and drafted the manuscript. C.F.D. performed the Comet Assay in sperm and analysed data related to DNA fragmentation. S.G.R. contributed to the coordination of the study, being involved in fish care and exposure. P.H. designed the study, interpreted the data and supervised the manuscript writing. All authors read and approved the final manuscript.

\section{Competing interests}

The authors declare no competing interests.

\section{Additional information}

Supplementary information is available for this paper at https://doi.org/10.1038/s41598-019-54368-8.

Correspondence and requests for materials should be addressed to M.P.H.

Reprints and permissions information is available at www.nature.com/reprints.

Publisher's note Springer Nature remains neutral with regard to jurisdictional claims in published maps and institutional affiliations. 
(c) (i) Open Access This article is licensed under a Creative Commons Attribution 4.0 International License, which permits use, sharing, adaptation, distribution and reproduction in any medium or format, as long as you give appropriate credit to the original author(s) and the source, provide a link to the Creative Commons license, and indicate if changes were made. The images or other third party material in this article are included in the article's Creative Commons license, unless indicated otherwise in a credit line to the material. If material is not included in the article's Creative Commons license and your intended use is not permitted by statutory regulation or exceeds the permitted use, you will need to obtain permission directly from the copyright holder. To view a copy of this license, visit http://creativecommons.org/licenses/by/4.0/.

(C) The Author(s) 2019 